\title{
A Method for Calculating Single-Event Distributions for Point Source Alpha Emitters
}

by

W. E. Wilson

September 1977

Prepared for the Energy Research and Development Administration under Contract EY-76-C-06-1830

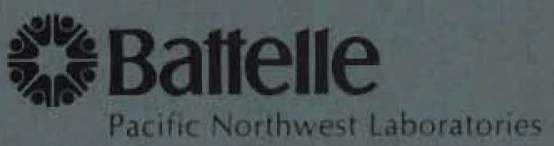




\title{
NOTICE
}

This report was prepared as an account of work sponsored by the United States Government. Neither the United States nor the Energy Research and Development Administration, nor any of their employees, nor any of their contractors, subcontractors, or their employees, makes any warranty, express or implied, or assumes any legal liability or responsibility for the accuracy, completeness or usefuiness of any information, apparatus, prucluct or process disclosed, or represents that its use would not infringe privately owned rights.

The views, opinions and conclusions contained in this report are those of the contractor and do not necessarily represent those of the United States Government or the United States Energy Research and Development Administration.

\author{
PACIFIC NORTHWEST LABORATORY \\ operated by \\ BATTELLE \\ for the \\ ENERGY RESEARCH AND DFVELOPMENT ADMINISTRATION \\ Under Contract EY-76-C-06-1830
}

\begin{tabular}{|c|c|}
\hline \multirow{2}{*}{\multicolumn{2}{|c|}{$\begin{array}{l}\text { Printed in the United States of Ame } \\
\text { Availabie from } \\
\text { Netional Technicai Iniormation Ser } \\
\text { U.S. Department of Commerce } \\
\text { S205 Port Royal Road } \\
\text { Springfieid, Virginia } 22151 \\
\text { e: Printed Copy \$_ Microfich }\end{array}$}} \\
\hline & \\
\hline -Pages & $\begin{array}{l}\text { NTIS } \\
\text { Seliting Price }\end{array}$ \\
\hline 001.025 & 34,50 \\
\hline $026-050$ & 55.00 \\
\hline $051-075$ & 55.50 \\
\hline $076-100$ & 55.00 \\
\hline $101-125$ & $\$ 6.50$ \\
\hline $126-150$ & 57.00 \\
\hline $151-175$ & 57.75 \\
\hline $176-200$ & 58.50 \\
\hline $201 \cdot .25$ & $5 d, 75$ \\
\hline $226-250$ & 59.00 \\
\hline $257 \cdot .75$ & 510.00 \\
\hline $2 \cdot 6-300$ & $\$ 10.25$ \\
\hline
\end{tabular}


BNWL -2254

$\mathrm{UC}-34 \mathrm{a}$

A METHOD FOR CALCULATING SINGLE-EVENT DISTRIBUTIONS FOR POINT SOURCE

ALPHA EMITTERS

by

W. E. Wilson

Battelle

Pacific Northwest Laboratories

Richland, Washington 99352 


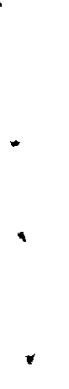

, 


\section{$\underline{\text { ABSTRACT }}$}

A method is described for calculating single-event distributions for point source alpha emitters. The method is based on computer simulation of alpha particle track structure by Monte Carlo techniques. 



\section{CONTENTS}

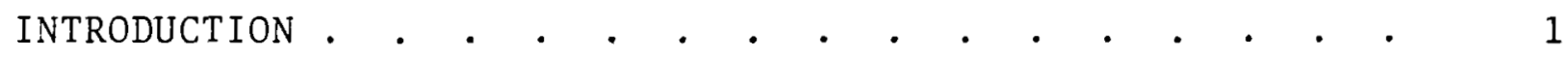

FORMALISM . . . . . . . . . . . . . . . . . .

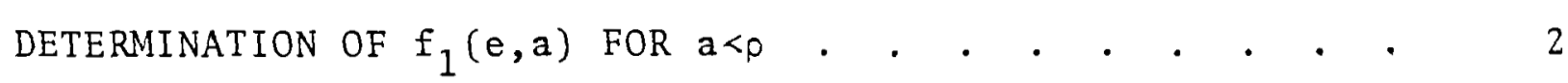

EFFECT OF TRACKS WITH a>p. . . . . . . . . . . . . 4 


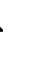

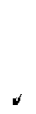




\section{A METHOD FOR CALCULATING SINGLE-EVENT}

DISTRIBUTIONS FOR POINT SOURCE ALPHA EMITTERS*

W. E. Wilson

\section{INTRODUCTION}

The theoretical nature of the distributions of energy deposited in microscopic volumes of matter by radiation fields have been extensively discussed by Kellerer ${ }^{1}$ and by Roesch and Glass. ${ }^{2}$ Experimental measurements have been reported by Glass and Braby, ${ }^{3}$ Gross, et al. ${ }^{4}$ and Glass and Roesch. ${ }^{5}$ For a general review, see Rossi. 6

It is the purpose of this note to describe a method for calculating the single-event distribution in energy imparted ${ }^{a}$ for a point source alpha emitter. The need for these distributions arises as a practical matter in the microdosimetry of internal emitters. 7

\section{FORMALISM}

The single-event distribution in energy imparted for a point source at a distance $r_{0}$ from a spherical volume of radius $\rho$ is (see Fig. 1),

$$
F_{1}(e)=\int_{\Omega} n(\Omega) f_{1}(e, \vec{r}) d \Omega
$$

where $n(\Omega)$ is the flux density, and $f_{1}(e, \vec{r})$ is the energy imparted

*This paper is based on work performed under United States Energy Research and Development Agency Conttact EY-76-C-06-1830.

${ }^{a}$ See ICRU-19 for definitions. 


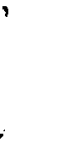


by a single track at $\vec{r}$ in the volume of interest. The volume of integration must extend over all solid angles for which $f_{1}$ is non-zero. Because of the finite range of the most energetic $\delta$-rays, this volume is slightly larger than the site volume. For an isotropic source of activity, $\mathrm{N}$,

$$
\begin{gathered}
n(\Omega)=\frac{\mathrm{N}}{4 \pi}, \\
\text { also } \mathrm{d} \Omega=\sin \theta \mathrm{d} \theta \mathrm{d} \phi .
\end{gathered}
$$

Because the problem has rotational symmetry, $f_{1}$ does not depend on $\phi$, therefore, Eq. (1) can be written

$$
F_{1}(e)=\frac{N}{2} \int_{0}^{\pi} \sin \theta \mathrm{f}_{1}(e, r, \theta) d \theta
$$

And, because of the rotational symmetry, the $f_{1}(e, r, \theta)$ can be completely characterized by $f_{1}(e, a)$, that is, all $f_{1}$ 's having the same impact parameter, a, are identical.

DETERMINATION OF $f_{1}(e, a)$ FOR $a<\rho$

Monte Carlo techniques were used to evaluate $f_{1}(e, a)$ for a $<\rho$ and for the range of alpha particle energies $1-6 \mathrm{MeV}$ and sites of radii 0.1-5.0 micrometers. The calculations were made using computer codes developed by Paretzke. ${ }^{8}$ Typical results are shown in Fig. 2 for $6 \mathrm{MeV}$ alphas passing at various impact parameters through a site radius $.25 \mu \mathrm{m}$. The distributions are only very roughly bell shaped because of low statistical accuracy in the calculations but are qualitatively in agreement with 
. 
experimental measurements by Glass and Roesch. ${ }^{5}$ No quantitative comparison was made because their experimental work was done with protons passing through a cylindrical site of tissue-equivalent gas.

We have approximated the distributions by a Gaussian function of the form,

$$
f_{1}(e, a)=\frac{1}{\sqrt{2 \pi} \sigma(a)} \operatorname{ExP}\left(-\frac{1}{2}\left(\frac{e-\bar{\Delta}(a)}{\sigma(a)}\right)\right.
$$

where $\bar{\Delta}(a)$ is the centroid or mean and $\sigma(a)$ is the standard deviation or width of the distribution.

The dependence of $\bar{\Delta}$ and of $\sigma$ on the impact parameter, $a$, obtained from the Monte Carlo calculations is shown in Fig. 3. The shape of the curve for $\bar{\Delta}$ indicates that it is linearly related to the track length inside the site ( $x$ in Fig. 1). This is to be expected because for the energies and site sizes considered here, the energy imparted to the site should nearly equal the energy lost by the alpha particle in passing through the site. That is,

$$
\bar{\Delta}(\mathrm{a})=\mathrm{L} \cdot \mathrm{x}(\mathrm{a})
$$

where $\mathrm{L}$ is the LET (stopping power) of the medium.

The dependence of the width of the distribution on radial position is also shown in Fig. 3. The ratio, $\sigma / \bar{\Delta}$, is constant out to within $0.1 \mu \mathrm{m}$ of the edge of the site, then it increases sharply. This sharp increase has been approximated by/exponential. Therefore, the width of the Gaussian distribution is given by 


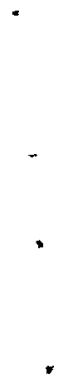

, 
$\sigma(a) / \Delta(a)=0.12$, for $0<a<\rho-0.1$,

and $\sigma(a) / \bar{\Delta}(a)=0.12+0.45 \exp (-107(r-a))$, for $\rho-0.1<a<\rho$.

Numerican integration of Eq.(2) using equations 3-6 is sufficient to evaluate single-event distributions for tracks which pass through the site.

\section{EFFECT OF TRACKS WITH $a>f$}

The contribution to $\mathrm{F}_{1}$ (Eq. (2)) for tracks passing outside the site is estimated entirely from Monte Carlo calculations and in the uniform flux or distant source approximation. Consider equations 1 and 2 and Fig. 1, for large $r_{0}$, we have

$$
\sin \theta \approx \theta \approx a / r_{0} \text {, and } d \theta=\mathrm{da} / \mathrm{r}_{0} \text {. }
$$

Therefore, in this approximation, the contribution, $F_{i}^{\prime}(e)$, for tracks passing outside the site is

$$
F_{i}(e)=\frac{N}{4 \pi r_{0}^{2}} 2 \pi \int_{\rho}^{\infty} a f_{1}(e, a) d a
$$

For numerical evaluation, the continuous integral can be approximated by a finite sum. Taking all $a_{i}$ of equal size and letting $g=4 \pi r_{0}^{2} F_{1} / N$, then,

$$
g(e)=2 \pi \Delta a \sum_{i} a_{i} f_{1}\left(e, a_{i}\right),
$$

$f_{1}\left(e, a_{i}\right)$ goes to zero rapidly for increasing $a_{i}>\rho$. Therefore, only a few terms with $a_{i} \sim \rho$ need to be considered in Eq. ( 9 ). 


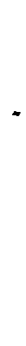

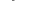


Because of this feature, $g^{\prime}\left(e, E_{\alpha}, a\right)=g(e) / \rho$ should be relatively independent of site size, $\rho$.

Single-event distributions, $g^{\prime}$, were calculated for tracks

with $\rho<a<(\rho+.3) \mu m$ for alpha energies over the range $1<E_{\alpha}<6$ $\mathrm{MeV}$ and for $0.1<\rho<5 \mu \mathrm{m}$. A summary of the results is shown in Fig. 4. The single-event distribution for tracks which pass totally outside the site is not significantly dependent on alpha energy and can be adequately approximated with an algorithm exponential in energy imparted, e. The amplitude and characteristic decay are, as expected, not strong functions of $P$; only the decay is assumed to vary linearly with site radius. Hence,

$$
\begin{aligned}
& \qquad \begin{aligned}
& g^{\prime}(e, a)=A \operatorname{Exp}(b e) \\
& \text { where } A= 0.12, \text { and } \\
& b=-0.92+0.175 \rho, \text { from least-square-fitting of } \\
& \text { Eq. (11) to the data presented in Fig. } 4 .
\end{aligned}
\end{aligned}
$$

Then,

$$
F_{i}^{\prime}(e)=\frac{N}{4 \pi r_{0}^{2}} A \operatorname{Exp}(\text { be })
$$

\section{APPENDIX}

\section{A. Description}

Subroutine SINGLE (see Appendix B for listings) does a numerical integration of Eq.(2) over the volume of the site using equations 3-6, and adds Eq. (14) at the end to represent the effect 


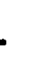

,

. 
of tracks which pass outside the site. The LET needed for Eq. (4) is evaluated from Brice's semi-empirical formulation for stopping power. 9 The LET for water is obtained from Bragg's rule and Brice's parameters for helium atoms in hydrogen and in oxygen and is calculated by the two function subprograms RLET(EA) and S (EALPH , I) .

This version of SINGLE returns single-event distributions for different values of $r_{0}$ (Fig. 1) beginning with $r_{0}=0$, and increasing in $1 \mu \mathrm{m}$ steps until the range of the alpha is reached, up to a maximum of 40 steps. (The range of a $5.15 \mathrm{MeV}$ alpha is about $39 \mu \mathrm{m}$ in homogeneous tissue or $\mathrm{H}_{2} \mathrm{O}$.)

\section{Definitions}

Al1 subroutine input-output for SINGLE is passed via COMMON. CMI (input)-EA is alpha particle energy in $\mathrm{MeV}$, RO is site radius in micrometers, $\mathrm{N}$ is a dimension parameter for the output arrays. CMO (output) $-F(I, J), I \leq I \leq N$ is the calculated result for the Jth $r_{0}\left(r_{0}(1)=0\right)$. $E(I, J)$ is the energy scale in $\mathrm{keV}$ for $\mathrm{F}(\mathrm{I}, \mathrm{J})$. $\mathrm{RE}(\mathrm{J})$ is the residual alpha energy in $\mathrm{MeV}$ at the center of the site for the Jth value of $r_{0}$. It is calculated in a continuous slowing down approximation using Brice's formulation for stopping power and taking discrete steps of not larger than $50 \mathrm{keV}$ energy loss. RANG is the total distance covered in the above approximation when the residual alpha energy decreases to less than $10 \mathrm{keV}$. KMAX is the actual number of cases or distributions to be calculated; it is the range +1 in integer $\mu$. 


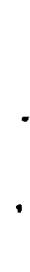


AVG(50), SIG(50) and $B(50)$ are scratch arrays.

Method

The array RE is calculated between lines 11 and 29 . (Unless otherwise specifically stated, references to the listing will be by line number rather than by statement number). The site radius is restricted to be larger than $0.1 \mu \mathrm{m}$ at 11 , other initial assignments are made at lines 13 ane 14. The basic loop for calculating an $R E$ is from line 15 to 27 , with an exit at line 23 if the residual energy becomes less than $10 \mathrm{keV}$. An integer distance in $\mu \mathrm{m}$ is assigned at 17 , a current value of stopping power (LET) in $\mathrm{keV} / \mu \mathrm{m}$ is obtained at 18. A decremental energy step is assigned at 20 . The code iterates between 18 and 24 taking no more than $50 \mathrm{keV}$ energy-1oss steps until a distance is accumulated equal to that assigned at 17 . When that happens $R E(k)$ is assigned at 25 , KMAX is updated to $K$. Upon eventual exit at line 23, KMAX will equal the last valid $\mathrm{K}$.

At 29, RANG is assigned to be the total distance accumulated. The evaluation of the KMAX single-event distributions is accomplished by the DO loop between lines 30 and 83 . Initialization takes place between 31 and 39. The energy scale is determined at line 38 , based on LET, site size and number of channels in the arrays. The energy array is assigned and the distribution array cleared between lines 40 and 43 .

Equation 2 is evaluated in two steps, the first step extends from lines 44 to 60 , the second from 61 to 78 . The first step does 


.


the integral in polar coordinates in 50 equal intervals in $\theta$ for $0<a<(\rho-.1)$. The second completes the integration, that is for $(\rho-.1)<a<\rho$ also in 50 equal intervals (the size of the latter intervals is generally much smaller than the former). This procedure is used in order to avoid artifacts in the calculated distributions arising from the numerical method. A very fine integration grid is required for tracks near the edge of the site. In the first step, equations 4 and 5 are evaluated at lines 54 and 55 and in the second step equations 4 and 6 are evaluated between 69 and 73. The actual integration (summation) is done at line 60 and at line 78.

$F_{1}^{\prime}(e)(E q .14)$ is evaluated by the function subprogram $\operatorname{SEP}(Y, R)$ and is added to the previous result at line 81 . 



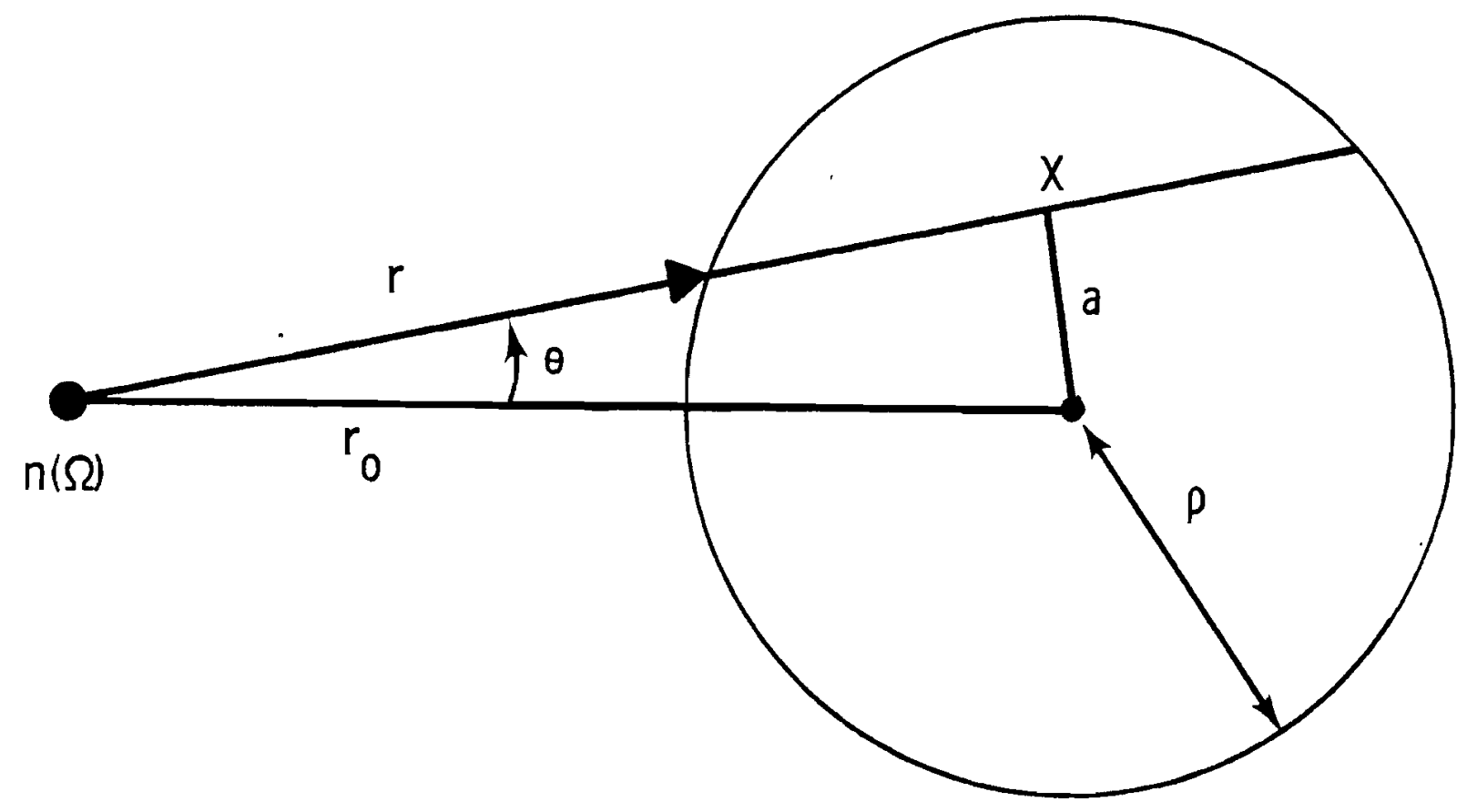

Figure 1

Schematic representation of the problem. A point alpha source emits $n(\Omega)$ alpha's per steradian. A typical alpha makes a track of length $x$ as it passes through the absorber site of radius $\rho$ at a distance $r$ from the emitter. In the text, the distance, $a$, is called an impact parameter. 


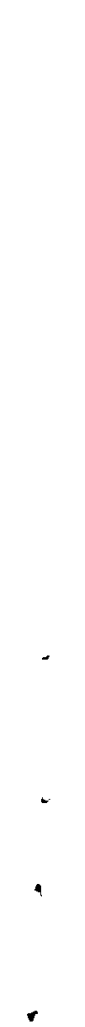




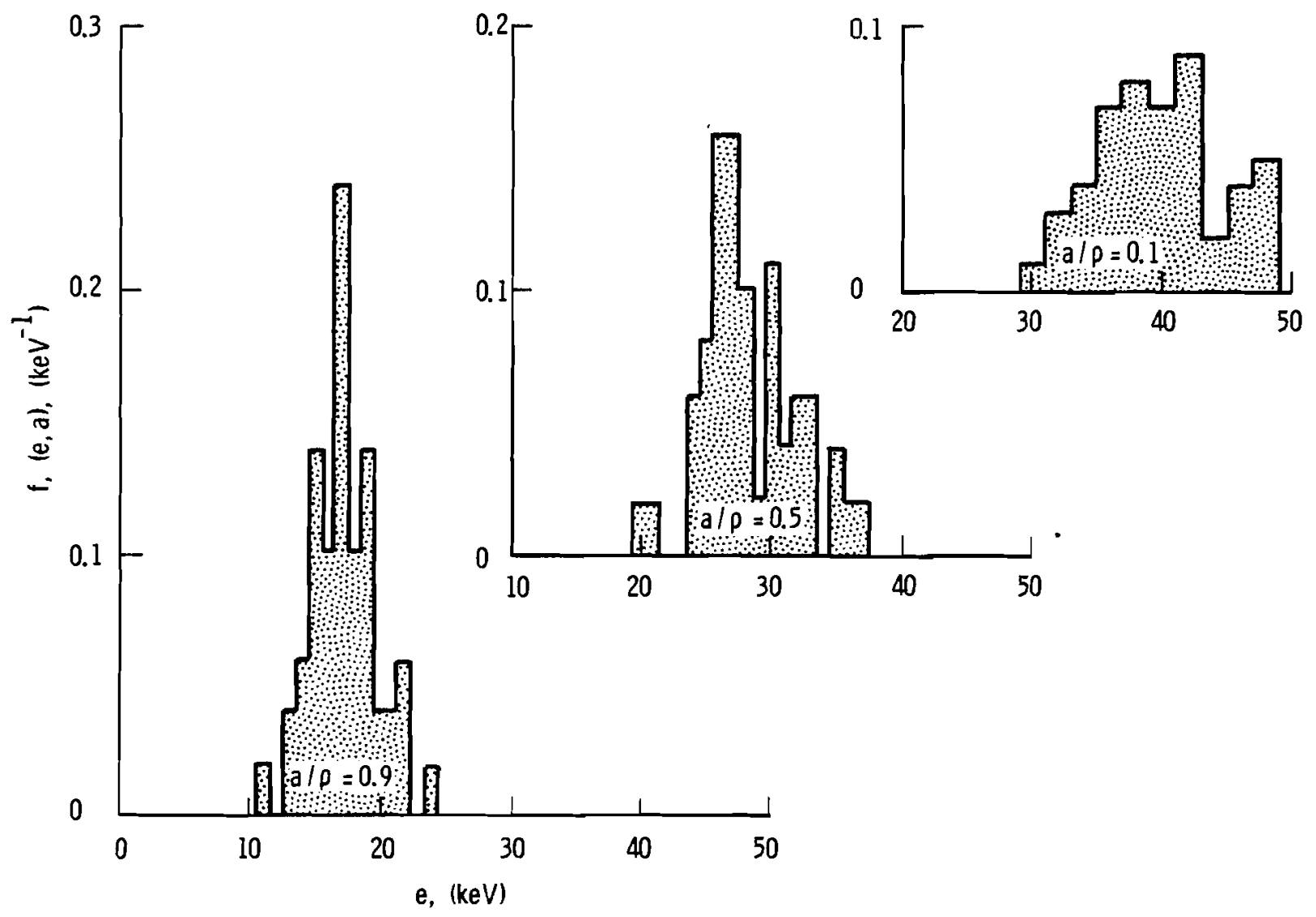

Figure 2

Energy deposition distributions for individual $6 \mathrm{MeV}$ alpha particles passing at different impact parameters through a site of $.25 \mu \mathrm{m}$ radius. 



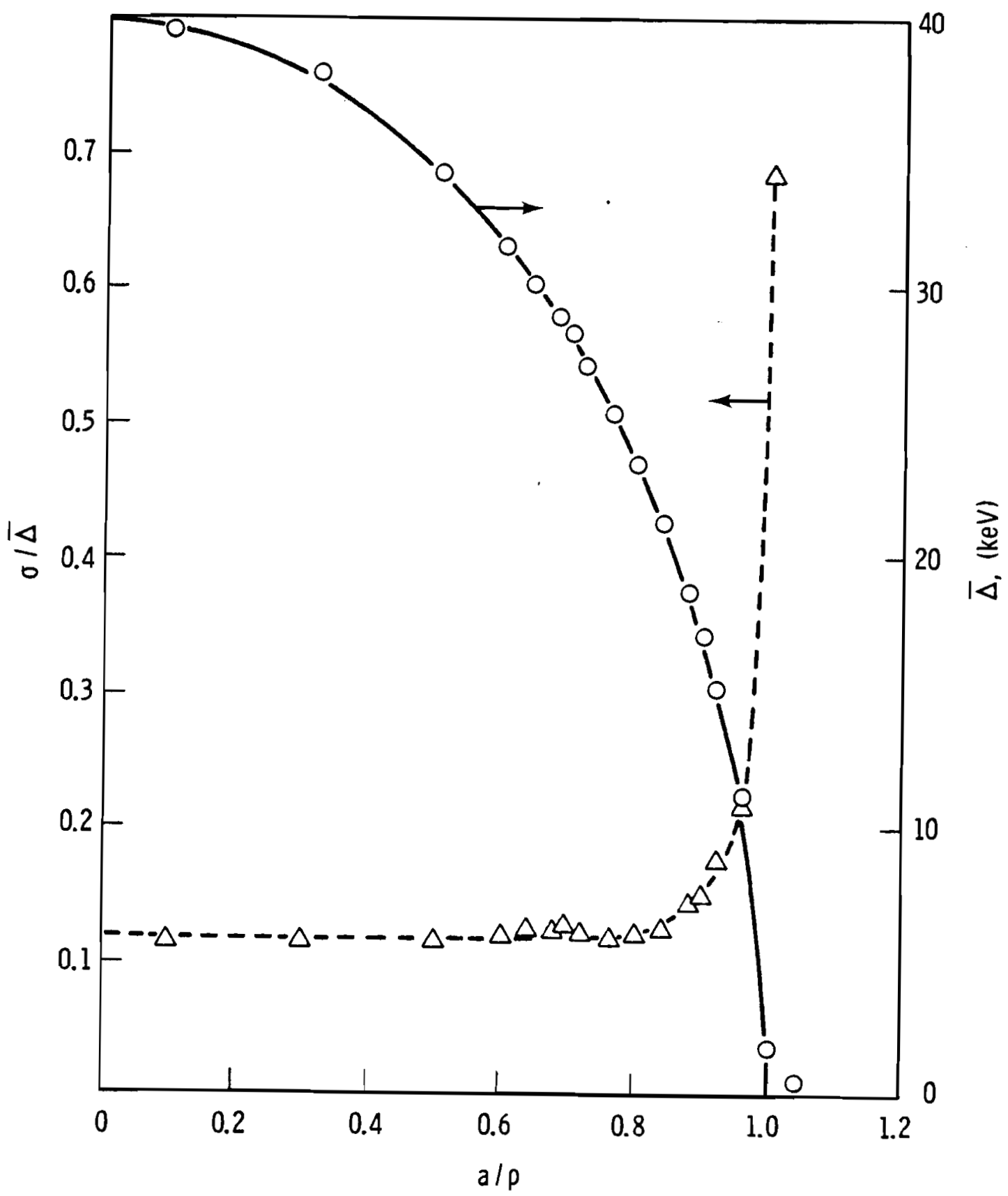

\section{Eigure 3}

Dependence of the mean, $\bar{\Delta}$, and width, $\sigma$, of energy deposition distributions on impact parameter for individual tracks passing through the absorber site. 


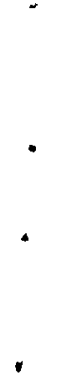


$-12-$

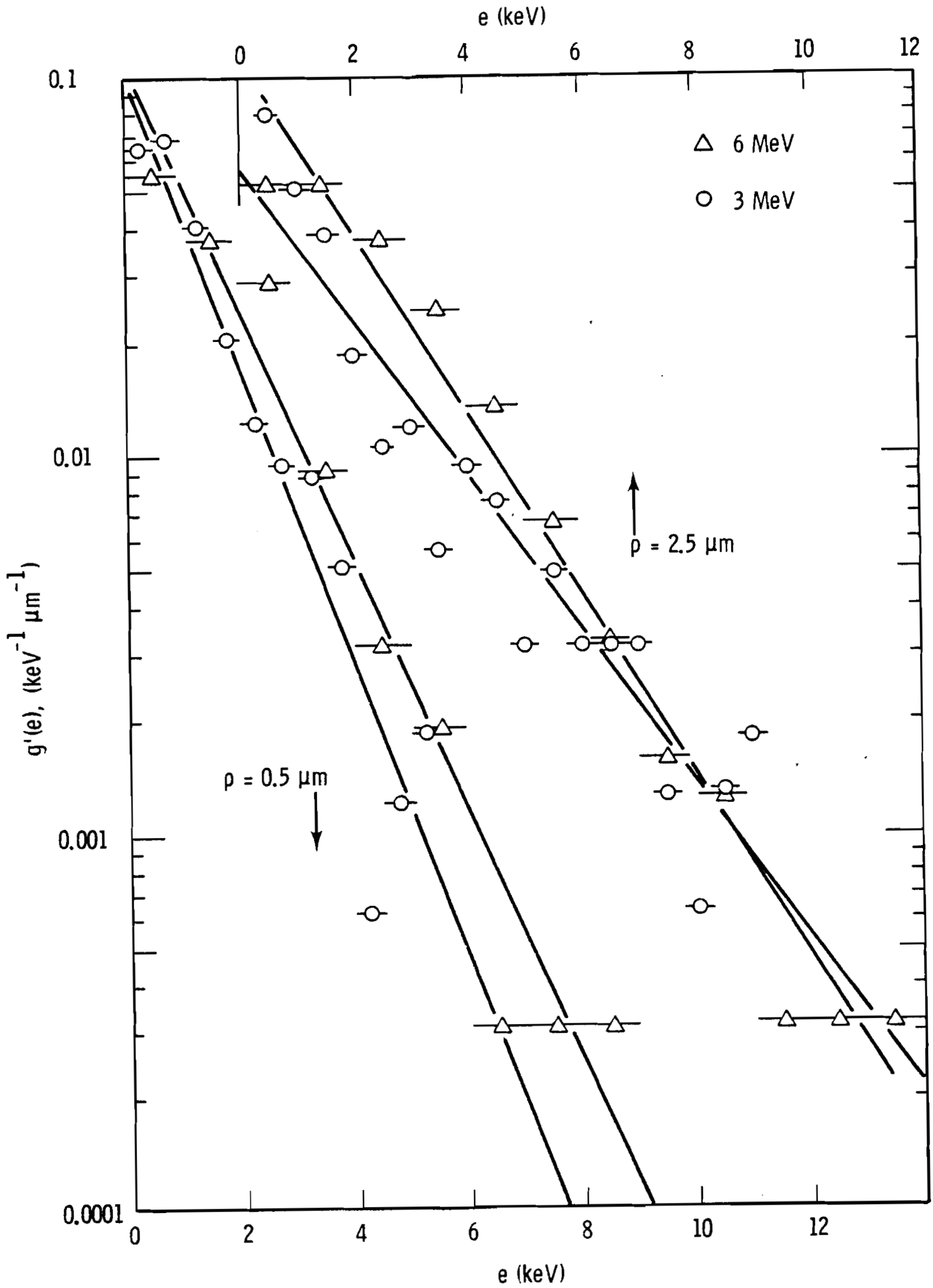

Figure 4

Energy deposition distributions (divided by site radius) in energy imparted for 3 and $6 \mathrm{MeV}$ alphas passing totally outside sites of radius 0.5 and $2.5 \mu \mathrm{m}$. 


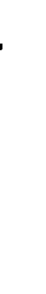


BNWL -2254

\section{REFERENCES}

1. A. M. Kellerer, Analysis of Patterns of Energy Deposition; A Survey of Theoretical Relations in Microdosimetry. In Proc. Second Symposium on Microdosimetry (H. G. Ebert, ed), p. 107134, EURATOM, Brussels, 1970.

2. W. C. Roesch and W. A. Glass, "Energy Deposition Distributions," Radiat. Res. 45, 1 (1971).

3. W. A. Glass and L. A. Braby, "A Wall-less Detector for Measuring Energy Deposition Spectra," Radiat. Res. 39, 230 (1969).

4. W. Gross, B. J. Biavati and H. H. Rossi, "Microdosimetry of Directly Ionizing Particles with Wall-less Proportional Counters," In Proc. Second Symposium on Microdosimetry (H. G. Ebert, ed), p. 249-263, EURATOM, Brusse1s, 1970.

5. W. A. Glass and W. C. Roesch, "Measurement of Ionization Distributions in Tissue-Equivalent Gas," Radiat. Res. 49, 477 (1972).

6. H. H. Rossi, "Microscopic Energy Distribution in Irradiated Matter." In Radiation Dosimetry, Vol. I, Fundamentals. (F. H. Attix and W. C. Roesch, ed), pp. 43-92, Academic Press, 1968.

7. W. C. Roesch, "Microdosimetry of Internal Sources," (Submitted to Radiat. Res. for publication.

8. H. G. Paretzke,"Comparison of Track Structure Calculations with Experimental Results." In Microdosimetry, Proc. Fourth Symposium on Microdosimetry (H. G. Ebert, ed), EURATOM, 5122 d-e-f (1973).

9. D. K. Brice, "Three-Parameter Formula for the Electronic Stopping Cross Section at Non-relativistic Velocities," Phys Rev. A 6 , 1791 (1972). 
-

.

x 
APPENDIX A 


\section{'}


1

5

10

15

20

25

30

35

40

45

SUBROUT INE SINGLE

CC- THIS VERSION CALCULATES PROBILITY DENSITY IN ENERGY IMPARTED

CC. FROM A POINT SOURCE, AUTH-WE WILSON, RICHLAND WA99352 (4/12/77)

COMMON /CMI/EA, RO,N

COMMON /CMO/E $(128,40), F(128,40), R E(40), R A N G, K M A X$

DIMENSION AVG $(50), 5 ! G(50), B(50)$

REAL L

DATA AVG/50*0,1,5lG/5000,1,8/5000,/

DATA C1/.1994711/,PI/3.141592654/

$F E X P(Z)=\operatorname{EXP}(A M A X 1(-293, \ldots A M I N 1(321 \ldots Z))$

$R=A M A X 1(70, .10001)$

CC- GET RESIDUAL ENERGY AT 1. MICRON INTERVALS

$R E A=E A$

$X=0$,

DO $10 K=1,40$

$R E(K)=0$.

$X K E F L O A T(K-1)$

5 LERLET(REA)

$Y=L$ AMAXI $(1, E-14,(X K-X))$

$D E=A M I N I(Y, A M A X I(50,50$, REA $))$

$X=X+D E / L$

REA $\triangle R E A=, 001 \bullet D E$

IF(REA.LE, .010) GO TO 15

IF $(X, L T$.

$R E(K)=R E A$

KMAX $=K$

10 CONTINUE

CC. LAST VALUe IS 'RANGe.

15 RANG $=X$

DO $90 K=1, K M A X$

REA $\approx R E(K)$

IF(REA,LE, .010) GO TO 90

RNG =F LOAT $(K-1)$

$C 2=4$. $P$ I*RNG*2

L IRLET (REA)

CC- SET UP ENERGY SCALE AND CLEAR FUNCTION ARRAY

IF (N,LE,O) RETURN

$D E=2,7 * L * R / F L O A T(N)$

$Y=0$,

$0020 \quad J=1, N$

$F(J, K)=0$.

$Y=Y+D E$

$20 \quad E(J, K)=Y$

CC. DO INTEGRAL UP TO R=.1

THI P !

IF(RNG,GE,R) THI=ASIN((R-.1)/RNG)

$D T H=, 02=T H 1$

THA-DTH/2.

DO $30 \quad l=1,50$ 


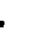


$T H=T H 1-, 5 \bullet D T H$

DO $50 \quad I=1,50$

$T H=P H+D T H$

$B(I)=S I N(T H)$

$A V G(!)=L * 2, * S O R T(R * 2-(R N G * B([)) * 2)$

$Y=-107, *(R-(R N G * B(1)))$

$Y=A M ! N I(Y, 0$,

$X=.12+.45 * F E X P(Y)$

$S ! G(!)=X+A \vee G(!)$

$a([)=B(I) \cdot D T H=C I / S I G(I)$

CONTINUE

DO $70 \mathrm{~J}=1, \mathrm{~N}$

DO $60 \quad l=1,50$

$60 \quad F(J, K)=F(J, K)+B(I) * F E X P(-, 5 *((E)(J, K)-A V G(I)) / S I G(I)) * 2)$

80

CC- ADD THE OUTS!DE TRACKS

$X=E(J, K)$

$F(J, K)=F(J, K) \quad+\operatorname{SEP}(X, R) / C 2$

70 CONTINUE

90 CONTINUE

85

IER $=0$

RETURN

END 
.

. 
APPENDIX B 


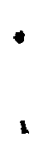




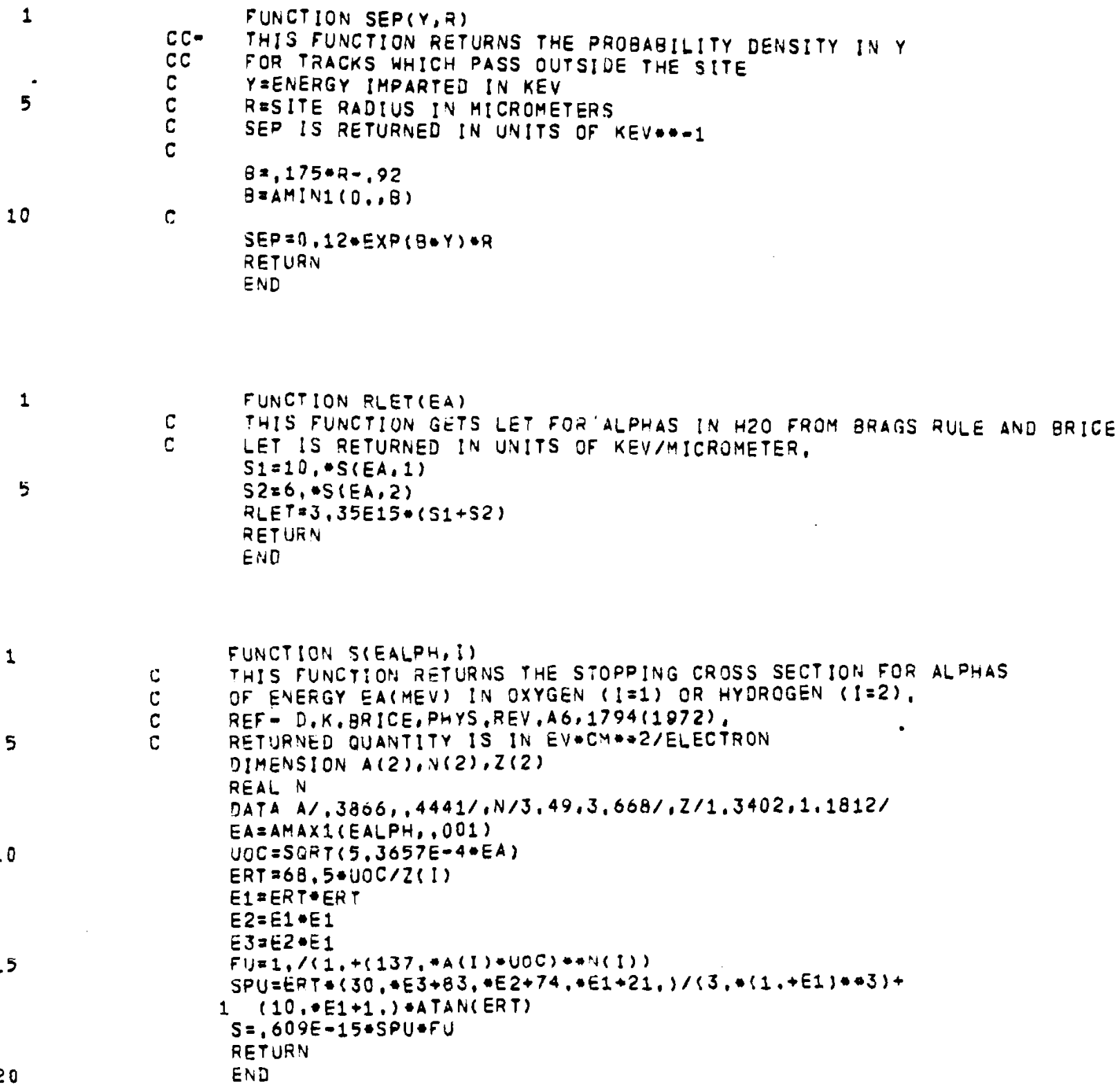

FUNCTION S(EALPH, I)

THIS FUNCTIOH RETURNS THE STOPPING CROSS SECTION FOR ALPHAS

OF ENERGY EA(MEV) IN OXYGEN $(l=1)$ OR HYDROGEN $(l=2)$,

REF - D,K, BRICE,PHYS,REV,A6,1794(1072),

RETURNED OUANTITY IS IN EV $* C M * 2 / E L E C T R O N$

DIMENSION A(2),N(2),Z(2)

REAL $N$

DATA A/.3806,.4441/,N/3,49,3,668/,2/1.3402,1.1812/

1

5 


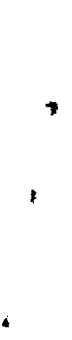


BNWL-2254

\section{DISTRIBUTION}

OFFSITE

1

ERDA Chicago Patent Group

A. A. Churm

ERDA Headquarters, Washington, D.C.

1 F. Hudson

$1 \quad R$. Wood

27 ERDA Technical Information Center

ONS ITE

ERDA Richland Operations Office

1 H. E. Ransom

Battelle Northwest

1 W. J. Bair

2 W. A. Glass

$1 \quad$ S. Marks

1 J. M. Nielsen

1 W. C. Roesch

5 W. E. Wilson

5 Technical Information Library 
r

.

, 